\title{
Unruly Objects - Material Entanglements in the Arts and Sciences
}

\section{Introduction}

\author{
Lucia Dacome \\ Institute for the History and Philosophy of Science and Technology, \\ University of Toronto, Toronto, Ontario, Canada \\ lucia.dacome@utoronto.ca \\ Meghan C. Doherty \\ Doris Ulmann Galleries and the Art and Art History Department, Berea \\ College, Berea, Kentucky, USA \\ dohertym@berea.edu
}

\section{Dahlia Porter}

School of Critical Studies, University of Glasgow, Glasgow, UK Dahlia.Porter@glasgow.ac.uk

\author{
Courtney Roby \\ Department of Classics, Cornell University, Ithaca, New York, USA \\ croby@cornell.edu
}

This volume considers the tension between the unruly material object and the equally unruly materiality of media used to investigate and engage with the natural world. It explores issues of flow and friction related to the creation and use of scientific and medical objects in mutable material media. While historians of science and medicine have frequently engaged in reconstructing these material engagements in terms of acts of ordering (in the museum context, for example), this volume sets out to examine the elements of unruliness inscribed into them. We argue that the history of producing and communicating scientific knowledge is structured around a tension inherent in material processes and transformations; it involves grappling with those materialities embedded in the study of the natural world and their translations into scientific objects. The cases examined in this collection accordingly encompass a wide range of visual and material tools, including images, specimens, models, printed texts, 
equations, tables, dioramas, prostheses, and diagnostic devices - perhaps even this very volume. One of our aims is to shed light on how unruliness has historically characterized both their coming into being and their performances as sites of knowledge. Quite naturally, such an undertaking is bound to include a variety of disciplinary perspectives. In focusing on the spaces where material entanglements reveal strain and stress, we promote conversations across a variety of fields, including art history, classics, the histories of science and technology, the histories of health, medicine and disability, literary history, and media studies. This volume appropriately originates out of a working group focusing on "unruly objects across the disciplines" at the conference Bibliography Across the Disciplines, held in Philadelphia on October 12-15, 2017. It brings together eight scholars from a variety of disciplines and institutional roles to engage in reflections on unruly materiality in the arts and sciences in different times and places.

Focusing on unruliness allows this volume's multidisciplinary vocation to extend both to its content and its methodological approach and scope. Individual essays address contexts as diverse as ancient Greece, early modern China and Europe, and twentieth-century North America. Presenting a wide range of case studies that exemplify how knowledge-making processes have historically been deeply entrenched in unruly materiality, the essays offer a variety of approaches with regard to practices, techniques, and modes of engagement with the natural world. The examples presented in the volume accordingly cover a wide spectrum of media - from papyri and parchment manuscripts to monitoring devices - and include tools as diverse as manuals aimed at training bodily movement, embroidered patterns that shaped the work of sewing hands, prostheses enacting views of gender and disability, and variant representations of "eternal" Euclidean forms propagated in manuscript and print, just to mention a few. Matthew Norton Wise has observed that "much of the history of the science could be written in terms of making new things visible or familiar things visible in a new way." Diverse as they might be, all the different contexts discussed in this volume show how processes involved in "making things visible" are deeply entrenched in unruly materiality.

In the past decades, historians of science and medicine have challenged the presupposition that there is knowledge before the medium. ${ }^{2}$ They have

1 M. Norton Wise, "Making Visible," Isis, 2006, 97/1:75-82, p. 75.

2 Among the voluminous literature, see, for instance, Susanne Bauer, Martina Schlünder, Maria Rentetzi (eds.), Boxes: A Field Guide (Manchester: Mattering Press, 2020); Carla Bittel, Elaine Leong, Christine von Oertzen (eds.), Working with Paper: Gendered Practices in the History of Knowledge (Pittsburgh: University of Pittsburgh Press, 2019); Adriana Craciun, Simon Schaffer 
instead emphasized that media, as material realia and as objects semantically encoded with visual as well as verbal information, are central to the creation of knowledge rather than merely functional to its dissemination. The essays in this volume equally foreground the intersection between media and materials as integral to the making of scientific knowledge. They draw attention to practices and techniques of translation, transformation, mediation, and negotiation in the context of material encounters across different media. While doing so, they expose how encounters and translations across media and materials were not smooth, uniform, and unobstructed processes and rather entailed forms of resistance and friction. The essays also engage distinct forms of materiality, from "things that talk" (singular, evocative objects like Andrew A. Gawley's prosthetics, analyzed by Jaipreet Virdi) to "black box" objects (the ubiquitous and disposable twentieth-century glucose monitors examined by Elizabeth Neswald). ${ }^{3}$ As a whole, this volume draws attention to materiality's recalcitrant character - its unruliness - and its epistemic implications. At the same time, it reveals the often arbitrary nature of the end product and the labor that went

(eds.), The Material Cultures of Enlightenment Arts and Sciences (London: Palgrave Macmillan, 2016); Joan Steigerwald (ed.), "Entanglements of Instruments and Media in Investigating Organic Life," focus section, Studies in History and Philosophy of Biological and Biomedical Sciences, 2016, 57; Carin Berkowitz (ed.), "Beyond Illustrations: Doing Anatomy with Images and Objects," forum section, Bulletin of the History of Medicine, 2015, 89; Iwan Rhys Morus, "No Mere Dream: Material Culture and Electrical Imagination in Late Victorian Britain," Centaurus, 2015, 57/3:173-191; Mary Terrall, Catching Nature in the Act: Réaumur and the Practice of Natural History in the Eighteenth Century (Chicago: University of Chicago Press, 2014); Pamela H. Smith, Amy R.W. Meyers, Harold J. Cook (eds.), Ways of Making and Knowing: The Material Culture of Empirical Knowledge (Ann Arbor: The University of Michigan Press, 2014); Pamela H. Smith, Benjamin Schmidt (eds.), Making Knowledge in Early Modern Europe: Practices, Objects, and Texts, 1400-180o (Chicago: Chicago University Press, 2007); Sachiko Kusukawa, Ian Maclean (eds.), Transmitting Knowledge: Words, Images, and Instruments in Early Modern Europe (Oxford-New York: Oxford University Press, 20o6); Soraya de Chadarevian, Nick Hopwood (eds.) Models: The Third Dimension of Science (Stanford: Stanford University Press, 2004); Harold J. Cook, “Time's Bodies: Crafting the Preparation and Preservation of Naturalia," in Merchants and Marvels: Commerce, Science, and Art in Early Modern Europe, edited by Pamela H. Smith, Paula Findlen (New York: Routledge, 2002), pp. 223-247; Nick Hopwood, Embryos in Wax: Models from the Ziegler Studio (Cambridge: Whipple Museum for the History of Science, University of Cambridge; Bern: Institute of the History of Medicine, University of Bern, 2002); Timothy Lenoir (ed.), Inscribing Science: Scientific Texts and the Materiality of Communication (Stanford: Stanford University Press, 1998); Michael Lynch, "Discipline and the Material Form of Images: An Analysis of Scientific Visibility," Social Studies of Science, 1985, 15/1:37-66.

3 Lorraine Daston (ed.), Things That Talk: Object Lessons from Art and Science (New York: Zone Books, 2004). 
into its making. By focusing on unruly objects, the volume projects media and materialities on to different social, affective and political spaces to highlight the creative potential of material insubordination.

Considerations on the implications of the orderly and the disorderly have typically informed reflections on the histories of collections, cabinets and museums. ${ }^{4}$ Traditional accounts of the history of collecting have customarily articulated a contrast between the disorderly array characterizing early modern cabinets of curiosity and the orderly arrangements of "modern" museum displays. In recent years, historians have nuanced such narrative in various ways. For instance, they have shed light on the rise of museums as the result of processes aimed at taming audiences and materials that took place at tensed crossroads between "the ordering forces of grand narratives" and the miscellany and disorder of local conditions at particular times and places. ${ }^{5}$ We maintain that a close look at materiality encourages us to revisit traditional historical

4 See, for instance, Sophie Thomas, "Collection, Exhibition and Evolution: The Romantic Museum," Literature Compass, 2016, 13/10:681-69o; Daniela Bleichmar, Peter C. Mancall (eds.), Collecting Across Cultures: Material Exchanges in the Early Modern Atlantic World (Philadelphia: University of Pennsylvania Press, 2011); Emma C. Spary, "Scientific Symmetries," History of Science, 2004, 42/1:1-46; Tony Bennett, The Birth of the Museum: History, Theory, Politics (London-New York: Routledge, 1995); Paula Findlen, Possessing Nature: Museums, Collecting, and Scientific Culture in Early Modern Italy (Berkeley: University of California Press, 1994); Oliver Impey, Arthur MacGregor (eds.), The Origins of Museums: The Cabinet of Curiosities in Sixteenth- and Seventeenth-Century Europe (Oxford: Clarendon Press, 1985).

5 Carin Berkowitz, Bernard Lightman (eds.), Science Museums in Transition: Cultures of Display in Nineteenth-Century Britain and America (Pittsburg: University of Pittsburg Press, 2017), p. x. See also, for instance, James Delbourgo, Collecting the World: The Life and Curiosity of Hans Sloane (London: Allen Lane, 2017); Staffan Müller-Wille, "Names and Numbers: 'Data' in Classical Natural History, 1758-1859," Osiris, 2017, 32/1:109-128; Luisa Calè, Adriana Craciun, "The Disorder of Things," Eighteenth-Century Studies, 2011, 45:1-13; Anna Maerker, Model Experts: Wax Anatomies and Enlightenment in Florence and Vienna, 1775-1815 (Manchester: Manchester University Press, 2011); Samuel J.M.M. Alberti, Morbid Curiosities: Medical Museums in Nineteenth-Century Britain (Oxford: Oxford University Press, 2011); Id., Nature and Culture: Objects, Disciplines and the Manchester Museum (Manchester-New York: Manchester University Press, 2009); Id., "Objects and the Museum," Isis, 2005, 96/4:559-571. Critical studies of archives and their organization have contributed to this analysis as well; see, for example, Francis X. Blouin, Processing the Past: Contesting Authority in History and the Archives (New York: Oxford University Press, 2011); Jesse Oak Taylor, "Auras and Ice Cores: Atmospheric Archives and the Anthropocene," Minnesota Review, 2014, 83/1:73-82; Geoffrey Swinney, "What Do We Know About What We Know? The Museum 'Register' as Museum 'Object'," in The Thing about Museums: Objects and Experience, Representation and Contestation, edited by Sandra Dudley, Amy Jane Barnes, Jennifer Binnie, Julia Petrov, Jennifer Walklate (Abingdon-New York: Routledge, 2011), pp. 31-45. 
configurations of the orderly and disorderly. ${ }^{6}$ Highlighting the cracks inherent in ordering acts, it invites us to turn such characterizations into the objects of scrutiny and investigation. Accordingly, we are concerned with the investigation of the broader history of unruliness as reflected in failed acts of fitting that accompanied engagements with the natural world in different periods and locations. In practice, this volume examines things that resist "sorting out," fall short of their expected functionality, or simply develop and perform in unexpected ways. By focusing on unruly materiality, it considers entangled practices of knowledge production in pedagogic, artisanal, mundane and quotidian as well as scholarly settings.

Many of the unruly objects tracked by contributors to this volume emerge from attempts to engage with ideas, categories, and observations of the natural world through material embodiments like books, dioramas, or diagnostic devices. These embodiments aim to compress a world's worth of possibilities into a small informational space, and so we might expect their creators to rely consistently on "minimalist" strategies: propagating only the "prototypical" polygon, the simplest typographical form of an equation, the correct configuration for the body's limbs, and so forth. To be sure, very often this is the case, as attested by a wealth of recent studies of strategies for ordering information through various media, drawn from a wide range of cultures. ${ }^{7}$ But in fact the papers in this volume trace some radical departures from those "minimalist" strategies: to be understood, algebraic equations need to be "exploded" rather than fit into the rigid lines of text (Rider); the "prototypical" polygon becomes a graph of looping curves (Netz); the "correct" configurations of bodily movement defined during the Ming dynasty are reshuffled and redefined in

6 For a similar approach, see Sophie Thomas, "'Things on Holiday': Collections, Museums, and the Poetics of Unruliness," European Romantic Review, 2009, 20/2:167-175.

7 See, for instance, Lorraine Daston (ed.), Science in the Archives: Pasts, Presents, Futures (Chicago: University of Chicago Press, 2017); Anke te Heesen, The Newspaper Clipping: A Modern Paper Object, translated by Lori Lantz (Manchester: Manchester University Press, 2014); Jason König, Greg Woolf (eds.), Encyclopaedism from Antiquity to the Renaissance (Cambridge: Cambridge University Press, 2013); Ann M. Blair, Too Much to Know: Managing Scholarly Information before the Modern Age (New Haven: Yale University Press, 2010); Nick Hopwood, Simon Schaffer, Jim Secord (eds.), "Seriality, and Scientific Objects in the Nineteenth Century," special double issue, History of Science, 2010, 48/3-4; Aude Doody, Pliny's Encyclopedia: The Reception of the Natural History (Cambridge: Cambridge University Press, 2010); Jason König, Tim Whitmarsh (eds.), Ordering Knowledge in the Roman Empire (Cambridge-New York: Cambridge University Press, 2007); Trevor Morgan Murphy, Pliny the Elder's Natural History: The Empire in the Encyclopedia (Oxford-New York: Oxford University Press, 2004); Richard Yeo, Encyclopaedic Visions: Scientific Dictionaries and Enlightenment Culture (Cambridge: Cambridge University Press, 2001). 
a revolutionary transition to the Qing dynasty (Basham); and Euclid's "eternal" Elements turn blue and gold as printers compete for market share (Anderson). This volume foregrounds precisely those qualities of scientific, medical, and technical explorations of the world that defy views of the "ideal" and the "normative" - the very qualities that most faithfully reflect those explorations' complex engagements with the material, economic, affective and political matrices that lend them meaning in their larger social and cultural contexts.

We are interested in exploring how unruly materiality provides access to these larger contexts. In order to do so, we build on the work of scholars who have drawn attention to the significance of technologies' breakages as points of entry into the power structures and political implications of scientific practice. Simon Schaffer, for instance, has shed light on the centrality of "disorderly hardware" and "states of disrepair" in scientific practice, highlighting how "labour politics of class and gender matter to repair work." ${ }^{8} \mathrm{He}$ has observed that "faults are defaults, yet instruments perform." ${ }^{9}$ Exploring the relationship between unruly materiality and performance registers the political stakes of knowledge making processes. Focusing on nation-building mythologies in Canada, Edward Jones-Imhotep has further shown how technological failures entered the Cold War's imagination, projecting perceptions of geo-political vulnerability onto the natural environment of the Canadian Artic. ${ }^{10}$ Essays in this volume similarly underscore the political implications of unruliness on different scales. Sarah Michel Scripps, for instance, reconstructs the changing visual grammar of science fairs in Cold War America as a window onto both concerns about national security and shifting attitudes towards notions of scientific expertise and views of scientific education. Focusing on seventeenth-century statecraft texts in China, Sarah Basham explores the creation and disruption of disciplining strategies that were used to project ideas of bodily order, and which encoded the promise of social advancement and economic reward at a time of political crisis and fear of social, political, and military upheaval.

In tandem with political concerns, some of the essays discuss how unruly materiality acted as a site of negotiation of gender conventions and expectations. Scripps traces how twentieth-century science fairs ended up reiterating

8 Simon Schaffer, "Easily Cracked: Scientific Instruments in States of Disrepair," Isis, 2011, 102/4:706-717. See also Simon Werrett, Thrifty Science: Making the Most of Materials in the History of Experiment (Chicago: Chicago University Press, 2019); Jutta Schickore, "EverPresent Impediments: Exploring Instruments and Methods of Microscopy," Perspectives on Science, 2001, 9/2:126-146.

$9 \quad$ Schaffer, "Easily Cracked" (cit. note 8), p. 707.

10 Edward Jones-Imhotep, The Unreliable Nation: Hostile Nature and Technological Failure in the Cold War (Cambridge, MA: MIT Press, 2017). 
gender stereotypes that sustained the masculinization of science education, despite the attempts to increase female participation. Mary Learner shows how the fine point of the needle served as a foundational tool for microscopy, inscribing women's manual domestic labor into the empiricist ethos of early modern natural inquiry. Virdi sheds further light on the relationship between materiality, bodies, and gender by reconstructing how prostheses operated as both unruly objects and arenas where social conventions and gender norms about masculinity could be performed and reiterated in the context of disability. Like Virdi, a number of essay contributors address the quintessential unruliness of human bodies. In particular, they highlight the implications of bodies' unpredictable and uncertain behavior with regard to their different engagements as sites of sensory and affective experiences or as objects of monitoring and disciplining. Basham singles out elements of unruliness ingrained in technical compendia depicting bodies in motion in early modern China. Neswald offers insights into instances of unruliness inscribed into the arts of gauging. While considering monitoring practices carried out through "unassuming" ordinary diagnostic devices like blood glucose monitors, Neswald highlights the tension between the material opacity of these objects and the embodied practices and affective experiences associated with their employment. In all these cases, a focus on human bodies reveals how materiality unsettles attempts at fitting and measuring, thus exposing and challenging the conventions at the basis of normative infrastructures. This volume explores how these acts of material resistance were articulated through the interplay of visual, verbal, and material media.

Interactions between verbal and visual knowledge have been a subject of intensive study at the intersection of the history of science, art history, and book history for several decades. While scientific and medical images were once largely treated as merely illustrative, they have now come to be regarded as fundamental modes of world-making. In recent years, scholars have equally engaged in articulating images' functional and ideological power in different historical settings. They have foregrounded the centrality of images and objects in the creation of medical and scientific knowledge, showing how knowledge claims could be codified and legitimated through the strategic deployment of specific visual conventions. ${ }^{11}$ The essays included in this volume build on exist-

11 The literature is vast. See, for instance, Anita Guerrini, "Counterfeit Bodies: Sébastien Leclerc, Anatomy, and the Art of Copying at the Paris Academy of Sciences," Word and Image, 2019, 35/3:277-295; Domenico Bertoloni Meli, Visualizing Disease: The Art and History of Pathological Illustrations (Chicago: University of Chicago Press, 2018); Birgit Schneider, Horst Bredekamp, Vera Dünkel (eds.), The Technical Image: A History of Styles 
ing conversations on scientific visualization but focus explicitly on the materiality of both objects of knowledge and visualizing media. By focusing on materiality, the volume demonstrates the unruly nature of visual and material media as knowledge making technologies, sites of negotiations of power, and arenas defining parameters of social as well as intellectual inclusion and exclusion. It also exposes how the fraught and often tense relationship between images, words, and objects translated into embodied experience. Basham, for instance, reconstructs how the integration of image, text, and readers' embodied modes of page-turning were meant to superimpose order on to moving bodies. At the same time, she shows how the re-use of the material tool of the woodblock, on which this act of ordering ultimately rested, became a source of unruliness in later instantiations of these texts. Here as well as in the other essays, careful attention is given to the modes of production and consumption of these media, from the manufacture of specialized paper (Anderson) to blood glucose monitors framing affective engagements (Neswald), and from stitch holes in botany pattern books (Learner) to the changing status of dioramas in science fairs (Scripps). This attention to multifaceted cases of unruly materiality across

in Scientific Imagery (Chicago: The University of Chicago Press, 2015); Nick Hopwood, Haeckel's Embryos: Images, Evolution, and Fraud (Chicago: Chicago University Press, 2015); Daniela Bleichmar, Visible Empire: Botanical Expeditions and Visual Culture in the Hispanic Enlightenment (Chicago: Chicago University Press, 2012); Ludmilla Jordanova, The Look of the Past: Visual and Material Evidence in Historical Practice (Cambridge: Cambridge University Press, 2012); Sachiko Kusukawa, Picturing the Book of Nature: Image, Text and Argument in Sixteenth-Century Human Anatomy and Medical Botany (Chicago: Chicago University Press, 2012); Hanna Rose Shell, Hide and Seek: Camouflage, Photography, and the Media of Reconnaissance (New York: Zone Books, 2012); Adam Mosley, "Objects, Texts and Images in the History of Science," Studies in History and Philosophy of Science Part A, 2007, 38/2:289-302; Stephanie Moser, "Making Expert Knowledge through the Image: Connections Between Antiquarian and Early Modern Scientific Illustration," Isis, 2008, 105/1:58-99; Lorraine Daston, Peter Galison, Objectivity (New York: Zone Books, 2007); Mario Biagioli, Galileo's Instruments of Credit: Telescopes, Images, Secrecy (Chicago: University of Chicago Press, 2006); Katharine Park, Secrets of Women: Gender, Generation, and the Origins of Human Dissection (New York: Zone Books, 2006); Katharine Anderson, "Looking at the Sky: Visual Methods in Victorian Meteorology," The British Journal for the History of Science, 2003, 36/3:301-332; Smith, Findlen (eds.), Merchants and Marvels (cit. note 2); Caroline A. Jones, Peter Galison (eds.), Picturing Science, Producing Art (LondonNew York: Routledge, 1998); Martin Kemp, “'The Mark of Truth': Looking and Learning in Some Anatomical Illustrations from the Renaissance and the Eighteenth Century," in Medicine and the Five Senses, edited by W.F. Bynum, Roy Porter (Cambridge: Cambridge University Press, 1993), pp. 85-121; Ludmilla Jordanova, "Gender, Generation and Science: William Hunter's Obstetrical Atlas," in William Hunter and the Eighteenth-Century Medical World, edited by W.F. Bynum, Roy Porter (Cambridge: Cambridge University Press, 1985), pp. $385^{-412 .}$ 
different media - and to the modes of material resistance that have historically marked the production, transfer, and consumption of knowledge in the arts and sciences - form the methodological core of the essays. This focus on mutable media provides a critical node to follow entangled materialities on the move, generating different topographies of material diasporas and processes of translation between words, images and objects, and their various scales of projection. Collectively, the essays presented in the volume foreground the way material, visual and verbal "grammars" develop to suit particular epistemological needs at particular times and places. At the same time, they also show how images and objects do not necessarily fit given grammatical grids. In general, the breadth of topics represented in the volume suggests a reassessment of how images and objects move within, between, and across media, crisscrossing languages and formats, and cross-referencing other forms of visualization and materials embodiments, while taking on a life of their own.

This volume participates in two major developments current in the history of science: investigations into the visual and material culture of science and medicine, and the ongoing interest in interdisciplinary approaches to the history of knowledge-making. The contributors have diverse institutional homes and disciplinary training, but they share an acute attention to the essential role of materiality in the creation and communication of medical, scientific and technical knowledge. They include curators, librarians, and academics at all stages of their careers from a range of academic disciplines, enriching the project's detailed attention to materiality in all its forms. By bringing a variety of perspectives to the analysis of different epistemic practices, these contributors offer new elements of reflection on and new insights into the unruliness ingrained in material media and material things, and the multiple layers of meanings accumulated through the composite histories that inhabit them. Whereas in many collections of essays a topical thread links functionally separate essays, our aim has been to actively promote dialogue across these disciplinary divisions and different realms of expertise in the engagement with media and materiality, and to integrate the result of this dialogue in the essays presented here.

\section{Acknowledgments}

The essays in this collection are developed from the papers presented at the Bibliography Across the Disciplines conference, held in Philadelphia, PA, on October 12-15, 2017. The conference was supported by the Rare Book School at the University of Virginia and the Andrew W. Mellon Foundation. We should 
like to take this opportunity to thank the organizers and administrators of the conference, particularly Barbara Heritage, Claire Reeger, and Donna Sy, and all the speakers and participants in our workshop. We are also grateful to the anonymous reviewers for their thoughtful and helpful comments and suggestions, and to Nuncius' editorial team for their valuable assistance during the preparation of this volume. 